\title{
The Poster Session as Fusing Theory and Practice in Art and Design Education: Exhibiting an Occluded Genre
}

Peter Thomas, Middlesex University and Grace Lees-Maffei, University of Hertfordshire

\begin{abstract}
While the academic poster has been used extensively in the sciences, its particular pertinence in art and design education remains unrecognised. Posters (outputs) and the poster sessions which accompany them (processes) form an 'occluded genre' in design education. The secondary literature about academic posters is typically 'how-to' rather than pedagogical analysis. We identify the benefits of using posters in design education, whether as formats for 'regenring' the conventional contextual studies essay, or as iterations towards essay work which draw on the skills students are developing in their design briefs and thereby bridging theory and practice, and accommodating diversity. Based on our pedagogical research in the UK and the Netherlands, this article reflects on how students respond to the benefits of the poster, and the poster session, and provides teachers with a clear rationale for their increased use in design education.
\end{abstract}

\section{Keywords}

Pedagogy, Design Education, Posters, Poster Sessions, Contextual Studies, Student Responses.

\section{Author Biographies}

Peter Thomas is Senior Lecturer in Academic Writing and Language for the Faculty of Arts and Creative Industries at Middlesex University. His research interests include: the generative role of writing in creative practice; academic literacies; interdisciplinarity and collaboration; and practice as research.

Grace Lees-Maffei MA RCA PhD FHEA is Professor of Design History at the University of Hertfordshire, chair of the TVAD Research Group's work on relationships between text, narrative and image, and the Researcher Development Working Group and Programme Director of the Professional Doctorate in Heritage. She wrote Design at Home: Domestic Advice Books in Britain and the USA since 1945, edited Iconic Designs: 50 Stories about 50 Things and Writing Design: Words and Objects and co-edited Designing Worlds: National Design Histories in an Age of Globalization, Made in Italy: Rethinking a Century of Italian Design and The Design History Reader.

\section{Introduction: Posters, Genre and Poster-Essay Regenring}

This article brings together two genres: the poster and the poster session. Both are communicative acts but one is an artefact (poster) and the other an event (poster session) centring on the artefact. For the purposes of our research, we defined a poster as a designed communicative object containing images and text which is intended to be displayed on a wall (or panel), and to be the focus of discussion in a poster session. Poster sessions involve the display and discussion of posters as evidence of research and knowledge. In HE, the poster session is similar to one at conference, in that it involves a poster maker discussing her work with viewers. However, it typically takes place for a shorter time, within a seminar for instance, and although there are different ways to run such sessions, discussion is often directed by a seminar leader, rather than just the interests of the discussants. The poster sessions we carried out in this research are described later.

Fiona English (2011) has contributed a social semiotic approach to the affordances of genre for developing students' writing, their knowledge generation and their approach to learning. For English, genre is itself a learning and teaching resource and 'regenring', or articulating the content of a text 
Accepted Version of 'The poster session as fusing theory and practice in art and design education: Exhibiting an occluded genre', Journal of Writing in Creative Practice, vol. 11, no. 2, pp. 233-259. https://doi.org/10.1386/jwcp.11.2.233_1

from one genre following the norms of another, affords new practices of knowing. For example, by relinquishing the essay format and re-presenting learning in the form of a play, students present their knowledge more actively, indicating deep learning rather than just information display.

Our focus in this article is the genre of the academic poster in the context of higher education (HE) art and design (A\&D), which we consider in light of English's work. Our interest in the academic poster is as an alternative to the essay, which we argue, appears increasingly unsuited to our context. A\&D students generally write essays as part of contextual studies, which typically focus on history and theory relevant to the students' field: fine art, photography, interior design, fashion design, product design, interaction design, etc. Assessment is made through essays of increasing length leading to a dissertation.

However, as will be spelled out in more detail later, such assessment practices present us with three issues: they do not adequately accommodate the diversity in HE today (see Snowball \& McKenna 2017); they contribute to, and at times exacerbate a disjunction between theory and practice in A\&D (see Biggs and Büchler 2012: 232); and they are over used in this context at the expense of other genres, such as posters, to our pedagogic detriment. These three problems prompted and shaped our research, and they make plain the pressing need to consider the genres we use, and the pedagogic potential in regenring. This article responds by identifying the benefits of the research poster, and calling for its increased use as an alternative genre, or as a complementary and iterative step towards an essay.

This article draws on primary and secondary research. Our review of literature on academic posters ranged across several disciplines, as we found that the poster is most common in the sciences and social sciences, and is comparatively under used in the arts and humanities (see Shalom 1993; Ensslin and Slocombe 2011). We also found that much of this literature is instructional rather than reflective or analytical ${ }^{1}$ (eg Harms 1995). We focussed our literature review (not supplied here) to the three research problems we mention above: diversity in HE; the theory/practice split in A\&D; and the underuse of posters in A\&D HE.

Our primary pedagogic research involved three groups of students (Photography and Interiors undergraduates in a North London university and Design Cultures postgraduates in a Dutch university). Our study was partly action research, to identify ways of improving the learning experience of our own students. We ran poster sessions with our 3 groups, and surveyed their views on the poster as an academic assignment. We analysed their feedback data using a grounded method, looking for points of consensus and divergence in the comments. The notion of genre, particularly the systemic functional linguistic understanding of genre as a social semiotic resource presented by English, was central to our interpretations of the data, and to our argument.

Our article begins with the methods we used in our primary research, and then we discuss our findings and what they can tell us about our research problems. Here, we evidence how our students found several aspects of the poster useful, including: the process of researching and making a poster; talking about it; and talking to other students about their posters in dedicated poster sessions. All these were particularly useful in developing ideas, and learning to express ideas.

\section{Method}

Drawing on our experience as lecturers in the field we carried out primary research to investigate the extent to which alternative genres, like the poster and poster sessions, can address these issues. The research was carried out in two HE institutions: one in the UK and one in the Netherlands, with three groups of students, at differing levels on different degree programmes. The groups were: (1) First year BA students in Interior Architecture and Interior Design at a university in London (32 students); (2) Second year BA students in Photography at the same university in London (33 students); (3) First year MA students in Design Cultures at a university in Amsterdam (23 students) ${ }^{2}$. We wanted to

\footnotetext{
${ }^{1}$ An exception to this is literature on linguistic analyses of discussion around the poster at conferences.

2 Our research was informed by using poster sessions in contextual studies with first year Graphic Design and Illustration BA Hons students, who are trained to make posters in their studio modules. Each student was asked to make a poster to communicate the design philosophy of a designer or illustrator of their choice. During the session, posters were displayed on the studio walls in chronological sequence, to create a timeline. The session
} 
Accepted Version of 'The poster session as fusing theory and practice in art and design education: Exhibiting an occluded genre', Journal of Writing in Creative Practice, vol. 11, no. 2, pp. 233-259. https://doi.org/10.1386/jwcp.11.2.233_1

access groups of respondents which varied in terms of level and programme of study, to help make our cohort representative of the diverse student body at $\mathrm{HE}$ art school as a whole. The undergraduate students were on studio-based courses, or courses with a primary focus on visual, object-based or spatial A\&D. The MA Design Cultures students included those with practice-based experience at BA level and in industry, and those from humanities backgrounds such as History and Sociology.

The research involved three main stages.

\section{Stage 1 - Poster Assignment and Poster Sessions}

In Stage 1, students were asked to carry out research, to design a poster to articulate the research, to display the poster in class, and to speak about it in a seminar session (example assignment brief available on request). The purpose of posters that each of our student groups was asked to research for and design was slightly different, and they were timed to take place at different stages in the students' courses (Table 1). Based on our experience of A\&D HE, we regard the variation in the purposes and timings of these poster assignments as typical.

\begin{tabular}{|l|l|l|l|}
\hline Group & Programme & Purpose of poster & Stage in the course \\
\hline 1 & $\begin{array}{l}\text { BA Interior } \\
\text { Architecture }\end{array}$ & $\begin{array}{l}\text { To articulate students' research into a } \\
\text { designer chosen by their module leader }\end{array}$ & $\begin{array}{l}\text { Year 1, start of second term of module } \\
\text { 'Key Interiors' }\end{array}$ \\
\hline 2 & $\begin{array}{l}\text { BA } \\
\text { Photography }\end{array}$ & $\begin{array}{l}\text { a) To articulate students' understanding of a } \\
\text { block of lectures/seminars }\end{array}$ & $\begin{array}{l}\text { Year 2, middle of first term, after first } \\
\text { block of lectures/seminars in 'The } \\
\text { Critical Image' module }\end{array}$ \\
\cline { 2 - 4 } & b) To articulate students' plans for an essay & Year 2, middle of second term \\
\hline 3 & $\begin{array}{l}\text { MA Design } \\
\text { Cultures }\end{array}$ & $\begin{array}{l}\text { To articulate research into a designer chosen } \\
\text { by the student for group presentation }\end{array}$ & $\begin{array}{l}\text { Year 1 (PG), start of first term of core } \\
\text { course 'Design, History, Culture' }\end{array}$ \\
\hline
\end{tabular}

Table 1: Purpose and Timing of Poster Assignments

Each poster session was similarly structured. Posters were displayed around the teaching spaces, ${ }^{3}$ and formed the focus of group discussion led by lecturers. Discussions involved approximately 10-15 students, and included the student poster maker/writer as an important, but not sole, speaker. To minimise potential anxiety, we did not ask students to make formal individual presentations to their groups. Our interest was in the poster as a designed visual artifact that articulates research, and as a prompt for discussion, rather than on presentation skills. Most A\&D HE students are familiar with group discussion focused on a visual artifact from the 'crits' or 'reviews' of practical work in their studio-based modules. Although there is debate about the effectiveness of crits (for example see Percy 2004), this style of session afforded contained, yet public, engagement with the posters.

In each session students pinned up their posters on the wall and then moved around the room looking at, and reading, one another's posters, before coming together for a whole group discussion based on them. In each case, the discussion was twofold: with the first-year undergraduates, discussion concerned the individual posters, designers and the development of design history as well as what makes an effective poster. In the case of the Masters level students, discussion encompassed both the contemporary debates represented in the posters and a reflexive discussion and effective poster preparation.

Our interest in surveying students about their perceptions and expectations of the poster stems from a conviction that as key stakeholders, their voices are fundamentally important. This is informed by an

enabled group-building and sharing knowledge, as well as introducing the histories of graphic design and illustration.

${ }^{3}$ In one case (group 1), the posters were displayed in a glazed corridor, instead of a class room, in what we called a 'Guerilla Gallery'. This was for logistical and pedagogical reasons: we could not secure a room booking for the duration of the session and we wanted to encourage the students of group 1 to display their research in a dynamic public setting. Here, other students and staff in the school could see the display, while the students who had made the posters could see their work being viewed by others. 
Accepted Version of 'The poster session as fusing theory and practice in art and design education: Exhibiting an occluded genre', Journal of Writing in Creative Practice, vol. 11, no. 2, pp. 233-259. https://doi.org/10.1386/jwcp.11.2.233_1

Academic Literacies imperative (see Lea and Street 1998; Lea 2004; Lea and Street 2006; Lillis 2003, etc.) to find sustainable and situated ways to develop student writing.

\section{Stage 2 \& 3 - Data Collection and Analysis}

For Stage 2, students completed a questionnaire ${ }^{4}$, designed to generate qualitative data about perceptions of different aspects of posters. The questionnaire data was summarized into themes. ${ }^{5} \mathrm{An}$ inductive approach was used for the data analysis, which involved close reading of the responses to identify recurring themes or patterns. Stages of coding, conceptualizing and categorising facilitated theorising the data and drawing conclusions. This approach was chosen (a) because it begins with the data collected (rather than a pre-selected thematic or conceptual framework) and (b) because it reveals not only the students' ideas, but also the materiality of their language, thereby foregrounding students' voices. In interpreting the data, we found a social semiotic approach to academic genre useful (see below).

There were discrepancies between the numbers of students in the poster sessions, the number of posters made and the number of questionnaires completed and returned to us (Table 2). The percentages we cite in the paper take these into account.

\begin{tabular}{|l|l|l|l|}
\hline Group no & No of students & No of posters & No of questionnaires \\
\hline 1 & 36 & 36 & 32 \\
\hline 2 & 33 & 23 & 33 \\
\hline 3 & 26 & 26 & 23 \\
\hline
\end{tabular}

Table 2: Discrepancies by Discipline

\section{Genre Theory}

In interpreting the data, we found it useful to consider aspects of genre theory, notably Fiona English's social semiotic approach to academic genres (English, 2011). In presenting genre as a resource rather than a list of DOs and DON'Ts (Derrida cited in English, 2011: 77), this approach presents a creative response to the issues we aim to address.

This theory has helped us to think about the possibility of change, in showing that by their nature, genres change and new ones emerge, and that 'tension between stability and change' is a defining feature of genres and how they are used (Berkenkotter and Huckin, 1993: 501). So the hegemony of the essay need not be a given.

It has also helped us to think laterally about genre, and to consider the possibilities or affordances that the material and practices of genres present. It encouraged us to interpret the comments from our respondents along the lines of benefits and drawbacks for the writer, and how they affect her decisions as she engages with the genre. It also foregrounded the fact that writing (and poster making) is a social practice, which has impact on others (the reader, for example).

Much genre theory is used to raise awareness of expectations that writers should meet when using a given genre. This is theory at the service of norming. The social inflection to the genre theory we have followed helped us to reframe such conventions as opportunities to transform (develop / improve) a student-writer's practice.

The theory showed us the position that genres take in relation to one another. For instance, the notions of genre systems and genre chains (Räisänen cited in Maclntosh-Murray, 2007) helped us to

\footnotetext{
4 The questionnaire asked students about their perceptions of posters (in general, their own, and those of their peers) and the process of creating one. It also asked students to reflect comparatively on posters and essays.

${ }^{5}$ All the data gathered from the students was anonymised, and consent to use the data was gained from each student involved, using a project information sheet outlining the research, and a consent form.
} 
Accepted Version of 'The poster session as fusing theory and practice in art and design education: Exhibiting an occluded genre', Journal of Writing in Creative Practice, vol. 11, no. 2, pp. 233-259. https://doi.org/10.1386/jwcp.11.2.233_1

understand the subtle differences in terms of purpose that posters have when they are used in a 'chain', as a preparatory stage in the development of another main text (e.g. an essay), compared to when they are the main text in their own right.

This understanding helped us see similarities between the process of moving along a genre chain, shifting from one type of text to another, and the process of regenring that Fiona English researched. We could say that shifting along a genre chain is a mild and predictable form of regenring that suggests that there are degrees of regenring, and that it is not a completely unfamiliar practice.

A related concept of occluded genres developed by Swales (1996: 45) was also helpful in our considerations about the poster and poster sessions. 'Academic occluded genres are, in part, those which support the research publication process but are not themselves part of the research record.'

\section{Results}

The responses to the questionnaire displayed a variety of views. The views we highlight in this section are either the most commonly repeated, or the most notable in some other way as will be explained. Feedback is summarised here in five sub-sections, each following one main theme, or aspect of the poster.

These headings also describe the poster-making process, in temporal stages. This was not predescribed in the questionnaire, but they emerged as having notable incidences as we analysed the responses. The categories are not mutually exclusive, responses often relate to more than one, but they provide a useful, general structure for summarising the findings.

We take each category in turn to show how the students responded to the different phases in the poster task and the impact the process had on their thinking and on their study experience. In order to give a flavour of how the students felt, we have used illustrative comments (in italics, with abbreviated identifiers in brackets).

\section{Research}

In terms of going about the research, gathering information and images for the poster and considering how best to address the assignment task, three common responses were that it called for a new way of thinking, was enjoyable and difficult.

Thinking in a new way is explained in a number of ways. As a design student, I can appreciate a transformation of the textual into the visual and therefore, I like the fact that we as students had to think differently about presenting some sort of research proposal and were challenged to present that information in an unusual but effective way. (Des Cult BF) The suggestion in comments like this seems to be that a visual outcome prompts a research process that is different to one prompted by a written outcome. It is seen by some as a process that enables a more lateral or divergent way of thinking than afforded by the research they do for written tasks. Some respondants explain this as a process of putting together (or adding to) a personal archive that is likely to be usable, beyond the immediate task, in studio-based work.

The new way of thinking also appears to relate to the immediacy of posters, and how this can help the researcher / designer with her own understanding of her research material. To realise if you really understand the subject and how will you try to make people understand it by your way as well. (Photo DK). The suggestion seems to be that communicating ideas visually through images, headlines, short chunks of texts and composition makes it possible for the researcher to literally see what they do or do not know. Kress (2008) would call this material realisation of meaning, a feature of the directness of multi-modal forms of communication.

Enjoyment is another feature of many responses. In answer to question $1^{6}$ approximately $65 \%$ mentioned liking or enjoying designing posters or finding the experience interesting or fun, compared to $13 \%$ who said the opposite. For some, enjoyment appears to stem from how posters allow for personal investment and expression. I always enjoy it because not only do I get a way to explore unknown designers but I also have a chance to express myself (Int AM).

${ }^{6} \mathrm{Q} 1$. How do you feel about designing posters? 
Accepted Version of 'The poster session as fusing theory and practice in art and design education: Exhibiting an occluded genre', Journal of Writing in Creative Practice, vol. 11, no. 2, pp. 233-259. https://doi.org/10.1386/jwcp.11.2.233_1

Some students also enjoyed how the visual nature of poster research frees the researcher from some of the logocentric constraints of essay writing. [Essays have] too much rules, you have to be careful. (Int PR). In several comments, another reason for enjoyment is that they see posters as creative. I enjoy designing posters, as we are given to opportunity to use creative license, which provides the different learning experience. (Des Cult GS).

Another reason to be cheerful about the poster is its relevance as an assignment type to their disciplinary context, because it allows research and design to converge. It connects my design background with the scientific research I do. (Des Cult KVL). This contrasts with a perception that while researching and writing essays, the students' design skills are curtailed or ignored.

Enjoyment in learning is not an unimportant factor, so these comments are more than merely nice to read. Czikszentmihalyi's (1997) notions of flow and optimal emotional states for learning suggest that generating understanding through posters has been an effective learning experience for these students.

Having said that students enjoyed researching and generating a poster, the process was clearly not easy. Words like 'difficult' and 'difficulty' were mentioned often (19 times), and 'struggle' was mentioned 6 times (notably in relation to being succinct or condensing information for posters). In most cases, the idea of difficulty was linked to positive comments about having learned a lot from the experience. On the one hand I feel excited because it is something different. On the other hand I felt stressed because I have never did poster. (Int MP)

This relates to the new way of thinking mentioned above, but points to a draw back, namely that it was unfamiliar, and so for some was a source of uncertainty. This can be understood in light of pedagogical theory like Zones of Proximal Development (ZPD), the psychological space where development of a learner's learning occurs, and in which struggle plays a key role (Vygotsky 1978, 86).

There was a sense in the comments that posters are versatile, in that they can be applied to the research process in different ways, for different purposes and at different moments, including: To summarise the topic. (Des Cult GM), or For generating ideas, Starting point for the essay. Good for structure and to research. It's bold and visually help stimulate ideas. (Photo AK) and [for] mood boards, ideas, presenting work. (Photo EK). They do not perceive the essay to have such versatility.

\section{Design}

In some repsects our categories of research and design overlap, as several comments refer to the possibility that design can be a form of research, not only a way of articulating it. I particularly like the fact that the visual content and informative content together create a 'designed narrative'. (Des Cult $\mathrm{JV}$ ). This ties in with the comments above about the research process being seen as creative. It also relates to literature on practice as research, which foregrounds 'different modes of knowing' (Nelson, $2013,51)$ and values 'material outcomes of practice as...representations of research findings in their own right' (Haseman cited in Nelson, 2013, 54).

Poster design for most of the students was a challenge; for some this was positive, It's a challenge to express the meaning of the topic precisely; I like that. (Des Cult NL). whereas for others negative, For me it was a challenge since I don't have a design background and I don't know how to work with the drawing programs. (Des Cult NK). Not all of our students were familiar with graphic design or poster making, which exposes the heterogeneous nature of art and design student cohorts, and makes clear that we cannot assume all art and design students have knowledge, skills and confidence necessary to produce all visual outputs to a high standard.

A challenge that almost all of the students focused on was that posters are limited in terms of the amount of information they can hold. You have a restricted framework in which all your information has to be squeezed which will lead to a lot of creativity but it will also create boundaries considering the provide of information. (Des Cult JV). By comparison essays were said by some to be where a topic can be explored more fully.

With such limitation can come frustration. Because of the limited space for text, it is not good for complex argumentation as in the abstract subjects like philosophy. (Des Cult ES). A small number of students said they felt that this makes posters unsuitable at university level. Some had negative 
Accepted Version of 'The poster session as fusing theory and practice in art and design education: Exhibiting an occluded genre', Journal of Writing in Creative Practice, vol. 11, no. 2, pp. 233-259. https://doi.org/10.1386/jwcp.11.2.233_1

associations with posters at school. I needed them during high school when the teacher clearly wanted 30 minutes to mark sheets. (Photo JA) ${ }^{7}$.

However, other comments suggest that brevity has its benefits, including that it enables a researcher to concentrate on key points and disregard minor details, and condense the thing you want to say and make it understandable in a few words. (Des Cult EK).

Another challenge students commented on is that despite limitations on content it can take a long time to design a poster. It is easy to think immediately text and images. If you want to be original it takes time and effort. (Int LM). Some students complained that they spent too long at the design stage, often because they wanted to perfect it, and interestingly this came from students who felt they had relevant design skills for the task, and those who did not.

Another challenge and key design feature of posters identified in a lot of comments was that posters rely on a careful combination of text and image. Such a balance is hard to achieve, and makes a poster a complicated design brief. Get it right, comments suggest, and the poster will be "easy to read" (Photo LW), whereas too much text will be boring and 'not inviting' (Des Cult BF), and too many images result in a 'childlike' poster (ibid.), which actually decreased serious tone of the provided information and the subject matter. (ibid.).

A feature of designing a poster that several respondents noted was that there appeared to be no correct or incorrect way to do it. Many saw this as a positive. ...its personal choice, there is no right or wrong, which is why it's so great and encouraging. (Photo KM). This can be understood in relation to the sense of freedom mentioned above, and is likely to stem from our decision in the assignment briefs not to specify how the posters should look ${ }^{8}$. However, there are plenty of dos and don'ts in the comments $^{9}$, e.g. Use different colours for different points so it doesn't get muddled up and is easier to read. Don't be too formal, not writing an essay! (Photo KM). This suggests our students actually have a very clear sense of what is right and wrong.

This readiness to judge good / bad poster-making practice could be seen as a contradiction of the sentiment that there is no right / wrong way to make a poster. We feel, rather, it suggests that they do not feel restricted by externally imposed poster design conventions, but they are prepared to set parameters for themsleves. This might be understood in light of Bakhtin's notions of discourse (1981: 342), with our students feeling unfettered by the authoratative discourse of poster design conventions, and able to follow their own internally persuasive discourse in setting their own parameters /

objectives. This could also be understood in relation to the comments above on spending too much time on design. Setting one's own parameters could be said to mean it is not easy to know when they have been satisfied, hence the extra time it seemed to take some of the students to make their posters.

\section{Production}

Respondents' comments on the production process include the fact that posters allow a variety of responses, including that they can be made digitally or by hand. However, some complained that posters can be expensive to produce (group 3).

The posters were produced in three ways: (1) design the poster on a computer and print it out onto an A2 sheet ( $63 \%$ of posters used this process); (2) hand written text and hand drawn images either directly onto an A2 sheet, or collaged onto an A2 sheet (15\% used this approach); (3) printed texts and images collaged onto an $\mathrm{A} 2$ sheet ( $21 \%$ did this).

In terms of which group prefered which approach, the MA Design Cultures posters were almost solely produced using approach 1 . Many of these were of a professional standard, with very high production values (Figs 1\&2). The undergraduate Photography and Interiors groups also favoured process 1, but the other two approaches were not uncommon, and each group seems to show a preference for one approach over another. $26 \%$ of the Photography students used handmade techniques, process 2

\footnotetext{
7 This highlights the fact that for some students posters are not new, and that in some cases, their prior experience of them has not been positive.

8 This contrasts with expectations about essays which we outline in some detail, and on which we run workshops.

${ }^{9}$ There are particularly large number of these in response to $\mathrm{Qu} .8$, on how to prepare for poster presentations.
} 
Accepted Version of 'The poster session as fusing theory and practice in art and design education: Exhibiting an occluded genre', Journal of Writing in Creative Practice, vol. 11, no. 2, pp. 233-259. https://doi.org/10.1386/jwcp.11.2.233_1

(Figs 3 \& 4). By contrast, a large percentage (44\%) of the Interiors posters combine computer- and hand-generated material (approach 3) (Figs 5 \& 6). 
Accepted Version of 'The poster session as fusing theory and practice in art and design education: Exhibiting an occluded genre', Journal of Writing in Creative Practice, vol. 11, no. 2, pp. 233-259. https://doi.org/10.1386/jwcp.11.2.233_1

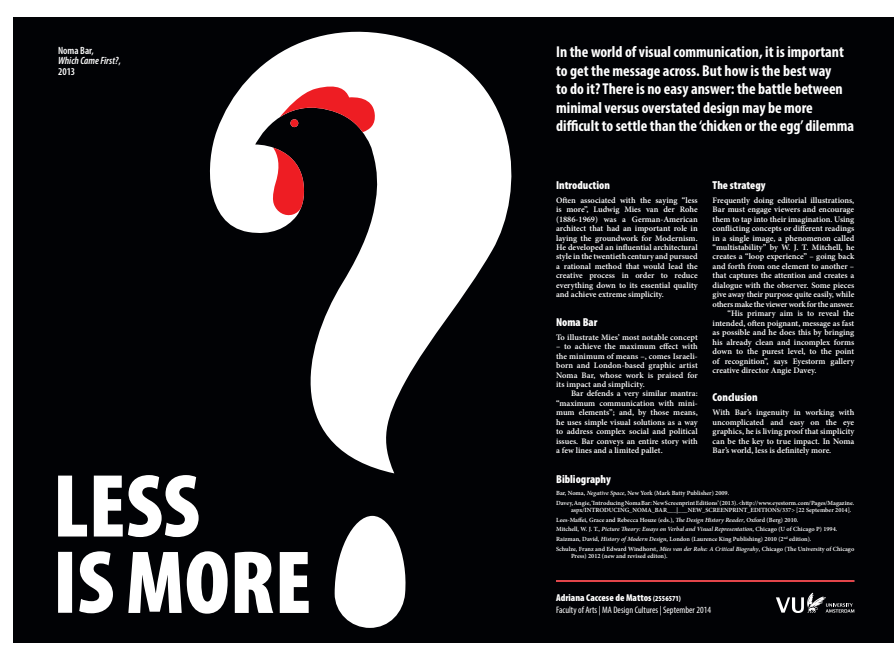

Figure 1 Poster from Des Cult group (AM)

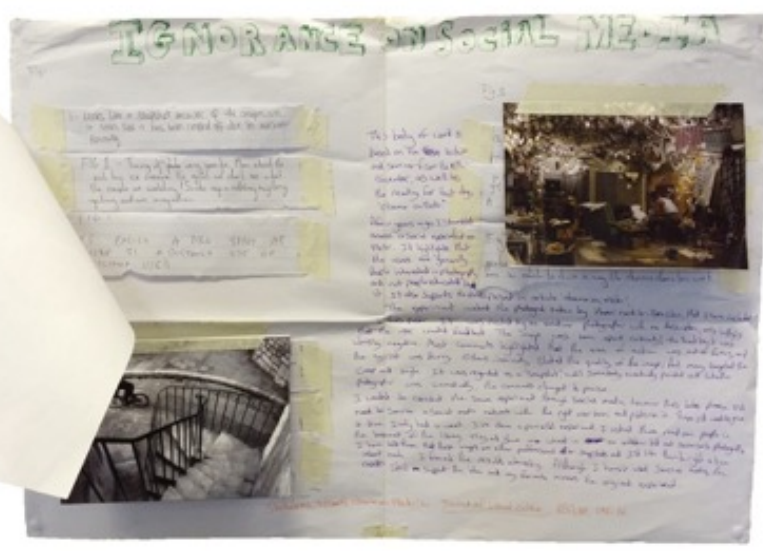

Figure 3 Poster from Photography group (ZR)

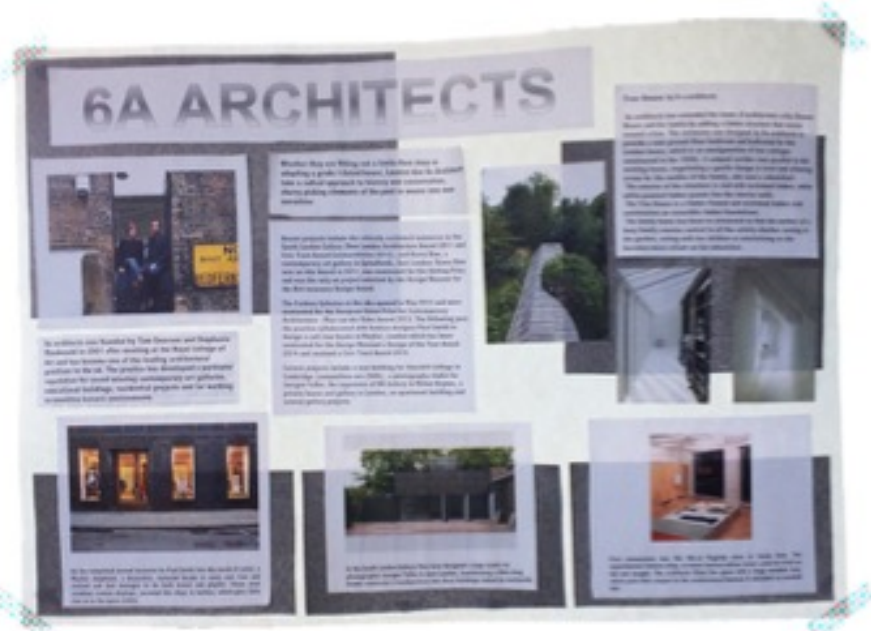

Figure 5 Poster from Interiors group (MC)

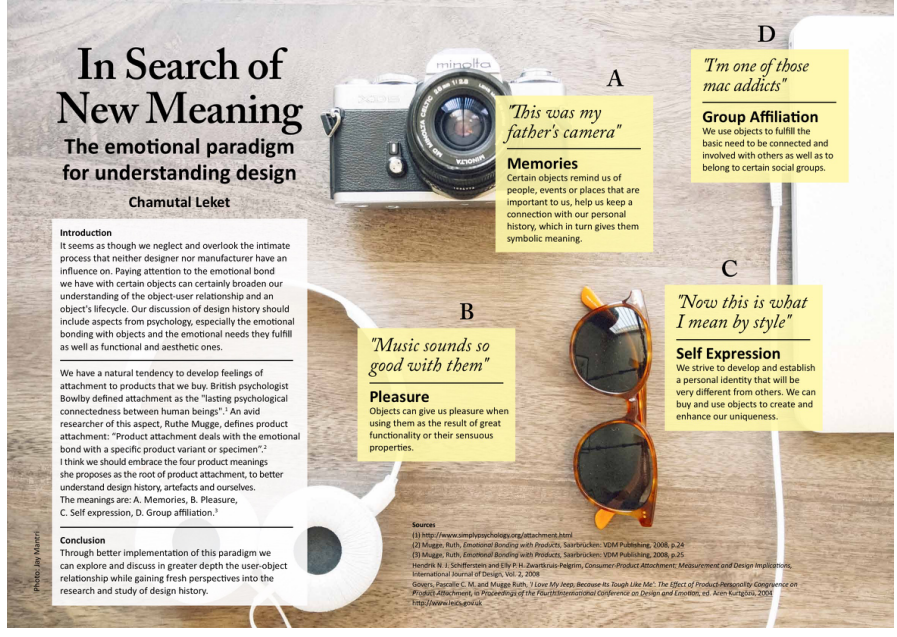

Figure 2 Poster from Des Cult group (CL)

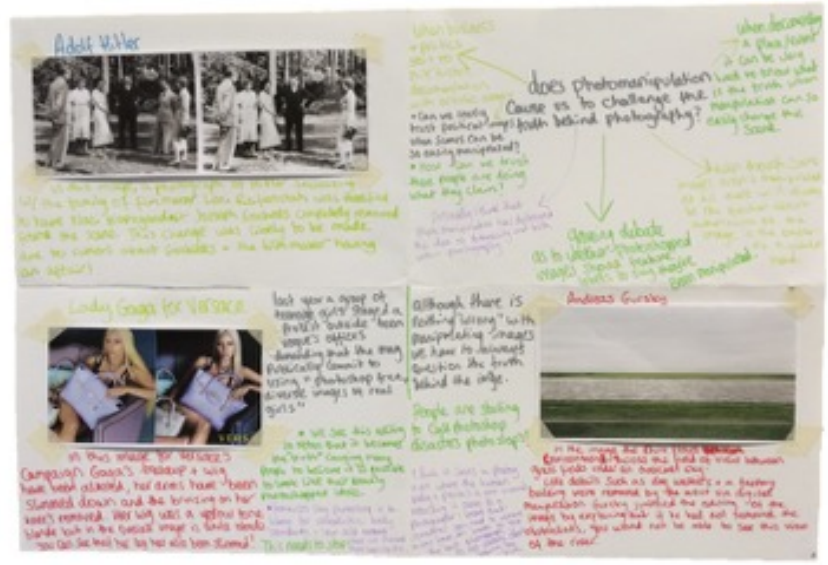

Figure 4 Poster from Photography group (KM)

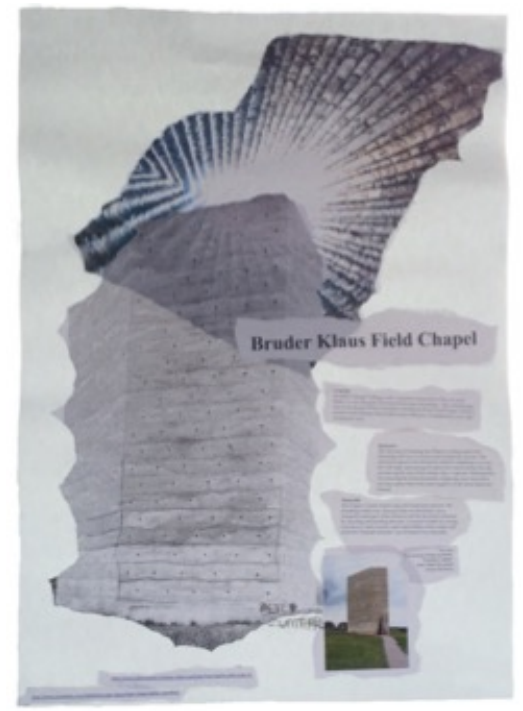

Figure 6 Poster from Interiors group (AK) 
Accepted Version of 'The poster session as fusing theory and practice in art and design education: Exhibiting an occluded genre', Journal of Writing in Creative Practice, vol. 11, no. 2, pp. 233-259. https://doi.org/10.1386/jwcp.11.2.233_1

In terms of comments about producing the posters, a small number complained about the expense or difficulty of printing a poster at A2 size. This difficulty is addressed in a number of posters through printing onto two A3 sheets (or in one case, $4 \times$ A4 sheets) instead of onto one A2 sheet.

There were comments about the importance of drafting the poster, or making 'preprints' before the final version. After printing my poster it turned out that the typeface used was rather small. You had to stand a bit too close to the poster to be able to comfortably read it. (Des Cult VL). Such comments relate most to the posters produced following approach 1 , which requires a transfer from digital to physical. They highlight the difference between the physical and the digital approaches, as when a poster is produced physically (e.g. processes $2 \& 3$ ), the scale of elements and the overall layout is already visible and there is no transfer.

Several comments focused on the importance of high production values and polish. I don't like making them by hand because I think printing it makes it look cleaner and more professional. (Int). For some, approach 1 is associated with professionalism because of the cleanness and clarity it makes possible. Keep it clean and simple to avoid a childish-looking poster (Des Cult BF).

Comments like this associate neatness with professionalism and seriousness, by contrast messiness, is interpreted as a sign of little effort and of childishness. This relates to comments (above) on how lack of control (e.g. getting the text-image balance wrong) is also childlike. For some students this equation of mess with poor quality caused worry. I feel nervous because I am a messy worker with bad handwriting. (Photo ZR).

For others, however, messiness ${ }^{10}$ means freedom from restrictions, and freedom to express themselves in a personal way. Most of the comments about this relate more closely to the sense of freedom felt during the design process than production, but there are a small number of comments about some of the more handmade posters, as appearing to be more personal, more natural, less technical and more handmade, make it more personal and unique (sic). (Int JN).

In some of the class discussions, it was felt that some of the slightly scruffier looking posters were more innovative in the ways that they encouraged the viewer to engage with them, for instance opening flaps to see a hidden message (Fig 7.). One student commented that having seen the other students' posters she wished she had used, [a] range of approaches (collage, drawing, etc.).

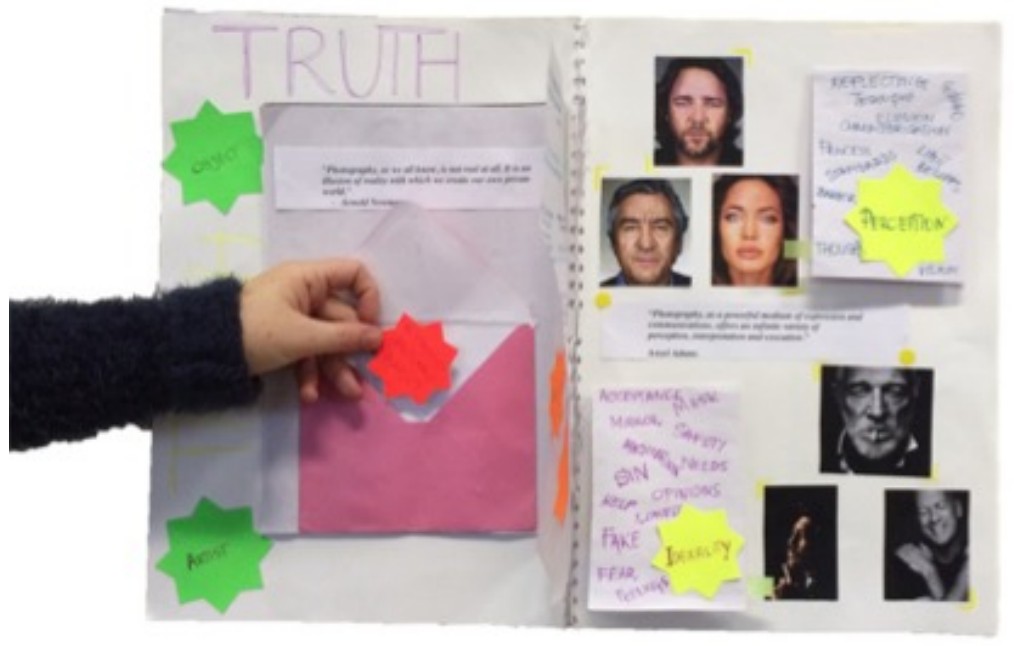

Figure 7. Poster from Photography group (MP)

\section{Delivery and display}

Comments that focused on the delivery and display of posters drew our attention to the fact that in asking students to design a poster and to speak about it in a poster session, we had in fact asked them to engage in two distinct although related communicative acts.

10 or what might be perceived as such by those who favour neatness 
Accepted Version of 'The poster session as fusing theory and practice in art and design education: Exhibiting an occluded genre', Journal of Writing in Creative Practice, vol. 11, no. 2, pp. 233-259. https://doi.org/10.1386/jwcp.11.2.233_1

Several comments were made about the positive impact that speaking about a poster in front of a group of people in a poster session can have on professional development. Every presentation prepares us for any job interviews etc. It helps us to get the confidence in standing in front of people and telling them what we want them to know. (Photo MP). However, a lot of students spoke of feeling nervous ${ }^{11}$, and not enjoying having to do this, particularly speakers of English as a second language.

Several respondents said they felt unprofessional in the poster session because they were not able to speak as fluently as they wanted. Stage fright. Tripping over your words, or worse, not finding them at all. It makes you look amateurish, but I'm rightfully so, because you are an expert (of some sorts) on your subject. (Des Cult LB). For some this was also because they were not satisfied with the quality of their poster....probably the fear of having the worst poster in comparison to other posters. (Des Cult EK). Countering this, some responded that the poster supported them in the poster session, because it held the information they had researched and reminded them what to say.

Another delivery and display-related topic commented on quite widely, and almost entirely positively, was the discussions in the poster session. [I liked] The work and discussion with other students and the way others are keen to share their view. (Photo AC). It was felt that the brevity of a poster can act as an engaging trigger to activate fuller consideration of a topic. if done right, it is a fun way to open up a debate. (Des Cult BF).

A particularly popular feature of this discussion was the feedback that poster makers received on their posters, and the ideas articulated in them. It was immediate (rather than delayed, as is the case with essay feedback via Turnitin, for instance), and for one group it fed forward, directly into an essay they wrote later in the term. We get to all view our process as a group. I have good feedback on poster and what I need to do. (Photo CB). For this group of students the poster served what we could call a semioccluded ${ }^{12}$ purpose, in that it supported the development of the assessed essay, as a formative stepping stone towards the final text.

As well as being immediate, feedback students received on their posters was the product of polylogal (Kerbrat-Orecchioni 2004: 3) discussion as several people participated in it, rather than monologue, as is the case with feedback on essays, which comes from the lecturer only. Among the participants, were the peers of the poster maker, which many respondents felt was important. [I like] Getting feedback from classmates and tutors, also sharing the information you know almost becomes a learning experience for others. (Photo RP).

\section{Reading}

The comments related to reading focus on the ways the posters were read in the poster sessions, and on more general considerations regarding reading posters.

Several comments highlighted how the poster sessions afforded the students' posters the opportunity to participate in what could be seen as a direct and synchronous communicative cycle, in that the poster was read and discussed by its readers with the poster-maker present, which meant the maker was able to engage immediately with readers about their responses to her work. This could be seen as a complete communicative cycle ${ }^{13}$.

The comparative nature of the reading the students did in the sessions was also commented on, and the peer-learning this afforded them. Because they read each other's posters and discussed them, they learned from the work one another had done, and the variety of ways they had done it. The

\footnotetext{
${ }^{11}$ As mentioned above, the poster sessions were organised to minimise anxiety as much as possible. The students were asked to put up their poster, then read the other posters, and engage in discussion about them, with lecturers steering the disucussion where necessary. None of the students were expected to speak at length in front of the whole group.

12 Semi-occluded rather than occluded as Swales (1996) describes it, because it was publicly displayed and discussed, so not fully hidden.

${ }^{13}$ By contrast, a typical university essay is indirect and asynchronous, as it is sent away to be read by a remote reader, whose feedback on it arrives some time later. This is often after it has ceased to be relevant to the writer, and with limited opportunity for the writer to engage directly with the feedback-giver about it.
} 
Accepted Version of 'The poster session as fusing theory and practice in art and design education: Exhibiting an occluded genre', Journal of Writing in Creative Practice, vol. 11, no. 2, pp. 233-259. https://doi.org/10.1386/jwcp.11.2.233_1

different styles of each one of us, and how each other understand the same things with other way. (Int MP).

The poster session lent the reading of posters the air of an event, and while this added energy and excitement, it also added distractions, which, according to one student, the poster-maker had to take account of in her design. The poster is presented in a room. The reader is standing and probably there is noise, or other people and other posters available in the room: distractions. Therefore the poster has to communicate a message quickly and clearly. The poster has to convince the reader. (Des Cult $\mathrm{JL})^{14}$. Related comments suggest that the readability of a poster is heavily dependent on the design being well executed, and that poor design will be off-putting and undermine effective reading.

Some of the comments pointed to how posters can communicate with an immediacy that more textual genres (like the essay) cannot. Their visual properties make it easier for the reader to understand. Taking in information in a way that is easier than just reading text. The images allow the audience to engage more and easier with the information. (Photo Al). However, others suggest the reader's understanding of the message can only ever be superficial because the poster's limited size means they inevitably miss important details. You don't have enough space to make nuances or write down detailed observations. (Des Cult ES).

One student characterised posters as being like photos and explained that this meant: you explore them as they visually engage you. The suggestion is that posters are open to interpretation, and can be read using your own judgment and imagination. This encourages a personal and deep investment in the reading that some visual practitioners find difficult to achieve with solely word-based texts. Allows the observer to connect more personally and interact with the topic discussed. (Des Cult AM). However, some comments point out that with openness to interpretation comes potential for uncertainty and imprecision.

\section{Discussion}

The results of our research suggest that genres like the poster and poster sessions have potential as alternatives to the essay in addressing the issues we identified above.

\section{Issue 1 - Diversity in HE and Posters as Levelling}

The diversity of students in contemporary HE is not being adequately accommodated by the essay. Snowball and McKenna (2017) observe that diversity is evident in HE in many ways. We particularly notice it in relationships that our students have with education (many are mature and some have SPLDs like dyslexia), and with English (many are L2 speakers). It is also apparent in the range of art and design disciplines represented in A\&D HE and in the disciplines that they draw on in their practices. Students bring with them, and develop diverse skillsets, and in the studio / practice components of their courses, they are encouraged to develop their own visual 'vocabulary' and to find their own ways of doing their design or art work.

Alternative genres, like poster assignments, poster sessions, and posters as semi-occluded, iterative steps towards essay assignments, can accommodate this diversity, providing scaffolding for students as they traverse their Zone of Proximal Development (Vygotsky 1978), while encouraging new ways of thinking. Evidence for this is clear in the numerous questionnaire respondents who commented on feeling empowered and motivated by having the opportunity to use their own voices, or ways of saying things, in their posters. This was partly due to the flexible nature of the poster, but also a consequence of our assignment briefs, which were purposefully open and did not prescribe formats or conventions.

Another feature commented on positively which suggests posters address diversity in relevant ways is the opportunity they gave students to engage with the subject matter through multiple modes: writing,

\footnotetext{
14 This comment contrasts with another by the same student on the comparative quiet of reading an essay, and the focus that this facilitates. The reader has the time to fully read and concentrate on your essay and there are likely fewer distractions. With an essay the reader has already made the choice to start reading your essay and is more likely to continue to the end. (Des Cult JL).
} 
Accepted Version of 'The poster session as fusing theory and practice in art and design education: Exhibiting an occluded genre', Journal of Writing in Creative Practice, vol. 11, no. 2, pp. 233-259. https://doi.org/10.1386/jwcp.11.2.233_1

images and speaking. This provides students various ways in to a topic; and the ways that one mode relates to another, and one peer's view counters another, aligns well with the 'dialectical process' (Oak 2000: 88) of design.

To accommodate diversity in an assignment means not taking anything for granted. For example the range of skillsets mentioned above, means that a lecturer cannot assume that all students are practiced poster-makers. In our case studies, not all of the students were designers, and even for those who were, not all of them were from design fields that use posters. The questionnaire results make clear that teachers need to accommodate (a) students who identify as designers and who feel confident using their design skills to produce posters, (b) student designers who feel less confident with the poster form either because of perceived higher expectations for designers and/or a disjuncture between posters made for design briefs and those made in contextual studies modules and (c) students who have no design training.

Regardless of how the non-designer and design students respectively feel, poster assignments and poster sessions develop students' design skills. They link, or integrate, the objects of study - the designs studied in A\&D contextual studies modules - with the ways in which they are studying them. Students participating in poster assignments and poster briefs are not only studying design, they are designing, and become practitioners at varying levels in this process. At the same time, though, they are learning about and through a genre which will probably be unfamiliar to them because of its relative underuse in A\&D HE. While we emphasize the poster as bridging theory and practice, the specific genre of the academic poster - as distinct from the poster produced in response to a design brief - is relatively unknown to the majority of incoming A\&D HE students. Poster assignments therefore fulfil a levelling function.

\section{Issue 2 - Theory/Practice Split and Posters as Manifestly Bridging Theory and Practice}

Regarding our second problem, our research indicates that the poster responds more effectively than the essay in bridging the theory/practice split bemoaned in the A\&D context. In researching, designing, making and displaying a poster, students manifestly bridge the theory/practice divide processually, materially and visually. Respondents commented on a new way of thinking that the poster seemed to demand of them, possibly a reference to this hybridity, and that it afforded the opportunity to respond to the brief with creativity. An element of this was seen in how the students set their own parameters for what makes an effective poster, which appeared to have a motivating effect for many. The poster promotes a personal response to a brief, like studio practice does, whereas essayistic norms actively mitigate against the personal.

Posters and poster sessions are particularly appropriate as classroom or studio activities which prepare design students for the industrial and cultural contexts they will enter upon graduation. A poster assignment involves research, selection, synthesis, editing, delivery and display, as does professional practice in A\&D. The peer learning of the poster session is allied with the crit and the client pitch. Poster assignments and poster sessions are consistent with English's 'regenring' in that they require a distinct approach to writing, based on concision and visual appeal, which introduces students to varieties of written genres and the need to develop their own skills in varieties of writing. Producing a poster requires a process of research, synthesis, editing and selection which is arguably more taxing than for an essay because so few words can be used in an effective and accessible poster design. Because students need to be so selective, the process of making a poster requires them to be in command of their material in order to identify the most essential points to communicate in the poster format.

The visual and material medium of the poster, when used iteratively in group poster sessions, can thereby benefit the development of students' writing skills. Numerous other genres and hybrids of texts afford similar benefits, to some extent (e.g. comics, visual essays, PowerPoint presentations, magazines, narrated photo essays, etc.). As well as indicating the benefits of an alternative genre, therefore, we hope our identification of affordances beyond this essay will also inform a method for finding other genres of benefit to A\&D HE.

The poster allows students the opportunity to see their work move through a full communicative cycle, with readers who engage with them about it. Again, this is similar to what happens in studio practice, in crits, client pitches and ultimately in exhibitions and publications. By contrast, the essay only completes part of the communicative cycle, as it is usually read by the lecturer alone, and is rarely 
Accepted Version of 'The poster session as fusing theory and practice in art and design education: Exhibiting an occluded genre', Journal of Writing in Creative Practice, vol. 11, no. 2, pp. 233-259. https://doi.org/10.1386/jwcp.11.2.233_1

seen again after submission. The poster is a real-life public communicative act, unlike the hidden and perhaps artificial academic exercise of the essay, therefore. Of course, publicness has drawbacks, like anxiety and perfectionism, and some of our respondents mentioned these. However, such issues are part of the target professional environment for many of our students, so learning to deal with them is beneficial.

Posters bring together theory and practice by providing a format that can be used in both contexts in a mutually reinforcing way; repeated use of this format hones skills further than would be the case for a format only used in theory classes (such as the essay, as distinct from the research report) or only used in studio classes (such as practical work), and by engaging skills which draw on both the practice of theory and studio practice/design skills (analysis, selection, synthesis, communication, manufacture, presentation - visual and verbal, etc.)

\section{Issue 3 - Underuse of Posters in A\&D HE: Posters as Standalone and Iterative Assignments}

Poster assignments, and poster sessions, can function as options for regenring the A\&D HE contextual studies essay, whether as outputs to replace the conventional essay, or as iterative tools in work towards a written assignment. In the latter case, the poster is not seen in the final output and fits the definition of an occluded genre, whereas when the poster is used as a focus for peer learning and talk, it is a highly visible physical manifestation of research, designed to be displayed. In both cases, the poster session forms a culmination: students read the work of others, and see their work read by others, and participate in peer learning and a completed cycle.

It is not clear precisely why posters are not used more often in HE art and design, but it might stem in part from a perception that for a number of reasons they are not quite good enough. For instance, comments from some of our respondents suggest that some academic posters are not sufficiently well designed to be taken seriously as 'proper' design output. They also suggest that posters are not sufficiently rigourous and detailed to be taken seriously as 'proper' academic texts. And some comments also suggest that because posters are used from elementary levels in education, they are often seen by pupils as light-touch, 'filler' activities rather than serious, core activities. These perceptions tie in with the sense that Swales reported that posters lack prestige (2004: 7).

However, in spite of these perceptions, most of our student respondents saw the creative, professional and educational potential of poster-based research and discussion.

Awareness raising and discussion would seem to lie at the heart of addressing the issue of the underuse of the poster (and overuse of the essay), and we hope that this article might contribute to this. Public discussion with other teachers about the genres we use and why we use them, which considers the affordances of the poster in particular, would be a good starting point; as would allowing time for similar discussion with our students.

This research has identified several important affordances of the poster, which we hope will help inform such discussions. Our respondents suggest these affordances include that posters and poster sessions can be: flexible as communicative tools, as they are multimodal and can take different forms; flexible in purpose, whether as an occluded genre or as the main output; less dependent on text and therefore more concise and accessible than more mono-modal texts like essays; capable of uniting theory and practice; afford a complete communicative cycle in terms of public engagement with the poster; encourage peer learning in terms of public discussion/display; rigorous, in that they are based on research and are publicly scrutinised; mechanisms for encouraging agency, with fewer perceived restrictions than more conventional genres such as essays; and focused and concise.

We hope that this list, and this article, will persuade teachers in A\&D HE of the benefits of taking a fresh look at the genres they set, and of integrating poster assignments and poster sessions in their teaching. Part of that, we also hope will involve engaging students in discussion about genres, and the benefits of making posters as part of their A\&D degrees, perhaps by including the above list of affordances within assignment briefs.

\section{Conclusion}

In challenging the hegemony of the essay, this article is essentially calling for a regenring of A\&D HE. It is asking stakeholder-lecturers to rethink the genres they intend their students to engage with, and 
Accepted Version of 'The poster session as fusing theory and practice in art and design education: Exhibiting an occluded genre', Journal of Writing in Creative Practice, vol. 11, no. 2, pp. 233-259. https://doi.org/10.1386/jwcp.11.2.233_1

in adopting a social semiotic approach to our research, we offer a means of coming to informed and creative decisions about such changes.

Proposing the need to find alternatives to the essay is not new (see Berkenkotter and Huckin on genre stability and change). Resistance to this change is unsurprising because the essay is regarded by many as possessing blue-chip qualities, including criticality, rigour and clarity, etc., which have served academia for a long time. Our proposal is not to deny this, but in the spirit of criticality and rigour, to draw attention to drawbacks with the essay that disadvantage many of its users, making it an inappropriate default genre in our context, and to call for lecturers in A\&D HE to consider alternative genres.

Finding alternatives is not easy, as there is a lot at stake, and as already mentioned (see Canagarajah and Lee on diversity in academic publishing) gatekeepers tend to be wary of the unfamiliar. So alternatives need to be well investigated and convincingly justified. We hope this paper does that, and goes some way to explain our confidence in multimodal alternatives, like the poster. In proposing the poster as an alternative, we have chosen an already existing, familiar and robust genre, and in including key stakeholders in our research, as well as existing literature, we have taken into account a range of relevant views on this topic.

The need to address the issues we present here is undeniable, as diversity is an increasing reality in the global HE sector, and the theory-practice split in A\&D will not be bridged on its own. The essay has had plenty of time and opportunity to demonstrate its capacity to address these, however, we find that within our context it is now proving to be inadequate to the task and something of an anachronism. So, we call for, and hope that our research contributes to the realisation of: an expanded repertoire of possible assignment types, including flexible and empowering alternatives like the poster; greater awareness among those who set assignments of the affordances of genres available to them; and creativity in their use of genres in the assignments they set. The bottom line is, it does not always have to be an essay (or follow essayistic norms).

\section{References}

Bakhtin, M.M. (1981) The Dialogic Imagination. Austin: University of Texas Press.

Berkenkotter C. and T. Huckin (1993) Rethinking Genre from a Sociocognitive Perspective. Written Communication. 10, (4), 475-509.

Biggs, M. and Daniela B. (2012) 'Text-Led and Object-Led Research Paradigms: Doing without Words' in Writing Design: Words and Objects, edited by Grace Lees-Maffei, pp. 231-141. London: Bloomsbury.

Canagarajah, S. \& Lee, E. (2014) Negotiating Alternative Discourses in Academic Writing and Publishing: Risk with Hybridity. Risk in Academic Writing: Postgraduate Students, their Teachers and the Making of Knowledge. Bristol: Multilingual Matters.

Cziksentmihalyi, M. (1997) Finding Flow: The Psychology of Engaging with Everyday Life. New York: Basic Books.

English, F. (2011) Student Writing and Genre. London and New York: Continuum.

Harms, M. (1995) 'How To... Prepare a Poster Presentation.' Physiotherapy 81, no. 5 (May 1995): 276-277.

Lea, M. and Street, B. (1998) Student Writing in Higher Education: An Academic Literacies Approach. Studies in Higher Education. 23, 2. June: 157-183.

Lillis, T. (2003) Student Writing as 'Academic Literacies': Drawing on Bakhtin to Move from Critique to Design. Language and Education, 17, 3: 192-207.

Lea, M.R. \& Street, B.V. (2006) The "Academic Literacies" Model: Theory and Applications. Theory Into Practice. 45, 4: 368-377.

Lea, M.R. (2004) Academic literacies: a pedagogy for course design. Studies in Higher Education. 29, 6: $739-756$.

Maclntosh-Murray, A. (2007) Poster Presentations as a Genre in Knowledge Communication: A Case Study of Forms, Norms, and Values. Science Communication. 28, 3. March: 347-376. 
Nelson, R. (2013) Practice as Research in the Arts: Principles, Protocols, Practices and Resistances. Basingstoke: Palgrave MacMillan.

Oak, A. (2000) It's a Nice Idea, but it's not actually Real: Assessing the Objects and Activities of Design. International Journal of Art \& Design Education 19 (1): 86-95.

Percy, C. (2004) Critical absence versus critical engagement. problematics of the crit in design learning and teaching. Art, Design and Communication in Higher Education. March, Volume 2, Issue 3: pp143-154.

Snowball, J.D. and McKenna, S. (2017) Student-generated content: an approach to harnessing the power of diversity in higher education. Teaching in Higher Education. 22, 5: 604-15.

Swales, John. 1996. 'Occluded Genres in the Academy: The Case of the Submission Letter'. In E. Ventola \& A. Mauranen (Eds.), Academic Writing: Intercultural and Textual Issues. Amsterdam: John Benjamins.

Swales, J.M. (2004) Research Genres: Explorations and Applications. Cambridge: Cambridge University Press.

Vygotsky, L. S. (1978) Mind in Society: The Development of Higher Psychological Processes. Cambridge: Harvard University Press 